ISSN 0103-8478

\title{
Cirrose biliar em felinos associada à ectasia do ducto cístico e desvios portossistêmicos extra-hepáticos
}

\section{Biliary cirrhosis in cats associated with cystic duct ectasia and extra-hepatic portosystemic Shunts}

\author{
Marcia Regina da Silva Ilha ${ }^{1}$ Alexandre Paulino Loretti ${ }^{2}$ \\ Claudio Severo Lombardo de Barros $^{3}$ Alexandre Mazzanti ${ }^{4}$ \\ Irene Breitsameter ${ }^{5}$
}

\section{RESUMO}

Descrevem-se três casos de cirrose biliar em felinos. o quadro clínico manifestado pelos animais afetados consistia em icterícia, vômitos, emagrecimento progressivo, prostração, anorexia e aumento de volume do abdome acompanhado de dor abdominal. Os principais achados macroscópicos incluíam fígado firme e com a superfície natural e de corte irregulares e de aspecto reticulado, ducto cístico acentuadamente distendido (ectasia), desvios portossistêmicos venosos extra-hepáticos ("shunts"), efusões cavitárias e carcaças em mau estado corporal. Histologicamente, havia fibrose periportal acentuada, dissecante, associada a infiltrado inflamatório mononuclear, proliferação ductal e retenção biliar. Em um dos casos, a coloração de BrownHopps revelou a presença de cocos gram-positivos associada à inflamação no lúmen ductal. A presença de bactérias intralesionais é um achado histológico raramente descrita no complexo colangite/colangio-hepatite felina e não tem sido descrita na cirrose biliar. Ectasia do ducto cístico e formação de desvios portossistêmicos extra-hepáticos são complicações incomuns do estágio terminal dessa síndrome. Cirrose biliar é a forma de apresentação menos comum do complexo colangitel colangio-hepatite felina. O número reduzido de casos dessa condição se deve ao fato de que a maior parte dos animais afetados por esse complexo morrem espontaneamente ou são submetidos à eutanásia antes de a doença progredir para a sua fase terminal. Desconhece-se a prevalência dessa enfermidade nas populações felinas locais das diversas regiões do Brasil.

Palavras-chave: cirrose biliar, fígado, complexo colangitel colangio-hepatite felina.

\begin{abstract}
Three cases of biliary cirrhosis in cats are described. Clinical signs included icterus, vomiting, weight loss, depression, anorexia and distension of the abdomen accompanied by abdominal pain. Main gross findings included firm liver with irregular capsular and cut surfaces and enhanced reticular pattern, marked distension of the cystic duct (ectasia), extrahepatic portosystemic venous shunts, cavitary effusions and thin carcasses. Microscopic lesions included severe periportal, dissecting fibrosis with lymphoplasmacytic inflammation, biliary proliferation and cholestasis. In one case, BrownHopps' stained slides revealed gram-positive cocci with associated inflammation inside the ductal lumen. The histological finding of intralesional bacteria in cases of feline cholangitis/ cholangiohepatis complex is reported only on rare occasions and has not been described for biliary cirrhosis. Dilation of the cystic duct and formation of portosystemic shunts are also unusual complications of this syndrome. Biliary cirrhosis is an uncommon condition since most cats die or are euthanatized before reaching the final stage of this progressive inflammatory hepatic disease. The prevalence of this entity in local feline populations remains to be determined in Brazil.
\end{abstract}

Key words: biliary cirrhosis, liver, cats, feline cholangitis/ cholangiohepatitis complex.

${ }^{1}$ Médico Veterinário, Mestre, Rua Paissandu, 385, apto. 201, Flamengo, 22210-080, Rio de Janeiro, RJ, Brasil. E-mail: ilha76@ hotmail.com. Autor para correspondência.

${ }^{2}$ Médico Veterinário, Mestre, Professor Assistente III, Setor de Patologia Veterinária, Departamento de Patologia Clínica Veterinária,

Faculdade de Medicina Veterinária, Universidade Federal do Rio Grande do Sul (UFRGS), Porto Alegre, RS, Brasil.

${ }^{3}$ Médico Veterinário, PhD., Professor Titular, Seção de Patologia Veterinária, Departamento de Patologia, Universidade Federal de Santa Maria (UFSM), Santa Maria, RS, Brasil.

${ }^{4}$ Médico Veterinário, Doutor, Departamento de Clínica de Pequenos Animais, UFSM.

${ }^{5}$ Médico Veterinário, Mestre, Hospital das Clínicas Veterinárias (HCV), UFGRS. 


\section{INTRODUÇÃO}

Complexo colangite/colangio-hepatite (CC/ $\mathrm{CH})$ é uma das causas mais freqüentes de doença hepática em felinos. Consiste em inflamação dos ductos biliares e do parênquima hepático circunjacente (DAY, 1995, GAGNE et al., 1996, WEISS et al., 2001). A terminologia empregada na classificação das doenças inflamatórias do fígado de gatos é confusa. Atualmente não há uma classificação de aceitação universal para as doenças inflamatórias do fígado de felinos (WEISS et al., 2001). Três formas dessa síndrome têm sido reconhecidas com base no aspecto histológico das lesões hepáticas que presumivelmente refletem as diversas fases da evolução clínica da enfermidade e o caráter progressivo da lesão hepática. Essas incluem a colangite/colangio-hepatite supurativa, a colangite/colangio-hepatite nãosupurativa crônica progressiva e a cirrose biliar ou colangite esclerosante. Cirrose biliar corresponde ao estádio terminal dessa entidade e está associada à inflamação crônica hepatobiliar que resulta em fibrose portal e hiperplasia ductal (EDWARDS et al., 1983, NAKAYAMA et al., 1992, DAY, 1995). Trata-se da forma menos comum dessa síndrome. O número reduzido de relatos de casos de cirrose biliar tem sido atribuído ao fato de que a maior parte dos animais afetados pela $\mathrm{CC} / \mathrm{CH}$ morre espontaneamente ou é submetido à eutanasia antes de a doença progredir para a sua fase terminal (DAY, 1995). A cirrose biliar é morfologicamente semelhante à colangite esclerosante e à cirrose biliar primária dos humanos (GAGNE et al., 1996). Etiologias infecciosas e processos imunomediados têm sido apontados como alguns dos fatores envolvidos na patogenia desse complexo de enfermidades hepáticas inflamatórias que acometem os felinos. Infecção bacteriana ascendente tem sido sugerida como uma das causas dessa síndrome Microrganismos pertencentes à flora comensal do trato gastrintestinal seriam capazes de invadir a árvore biliar e atingiriam o sistema hepatobiliar provocando inflamação peribiliar e fibrose hepática induzida por citocinas (DAY, 1995; CULLEN \& CHAPMAN, 2001). Em humanos, há fortes evidências epidemiológicas da associação entre a colangite esclerosante primária e as doenças inflamatórias intestinais (VIERLING, 2001). Essa hipótese também tem sido levantada para o CC/CH dos felinos (WEISS et al., 1996; LAPOINTE et al., 2000; WEISS et al., 2001). Colangite/colangio-hepatite não-supurativa e cirrose biliar corresponderiam a estágios evolutivos subseqüentes da síndrome, quando o agente infeccioso já teria sido destruído, mas mecanismos imunológicos perpetuariam a agressão ao sistema hepatobiliar. Colelitíase, trematódeos, protozoários e doença renal (síndrome nefrótica) também têm sido associadas ao CC/CH (DAY, 1995). Lesões inflamatórias no pâncreas e intestinos podem ocorrer simultaneamente àquelas observadas no fígado (WEISS et al., 1996). O quadro clínico observado nos animais afetados é consistente com insuficiência hepática e consiste em icterícia, caquexia, fígado firme e de aspecto nodular e ascite. A terapia a ser usada para os pacientes afetados pelo $\mathrm{CC} / \mathrm{CH}$ é determinada de acordo com o estádio da doença, que é determinado com base no exame histológico do fígado. O prognóstico dessa entidade é reservado em função de a condição usualmente ser refratária aos tratamentos empregados (DAY, 1995).

Diversos estudos abordando os aspectos clínico-patológicos, radiográficos e ultrassonográficos do complexo colangite/colangio-hepatite felina têm sido realizados (GAGNE et al., 1996; WEISS et al., 1996; GAGNE et al., 1999). No Brasil, no entanto, os estudos a respeito dessa enfermidade são escassos e limitam-se a relatos esporádicos sobre procedimentos diagnósticos e tratamento de casos isolados da doença em seus estádios iniciais (PANTIN et al., 1993; MOURA et al., 1996). A escassez de recursos diagnósticos nos estabelecimentos veterinários, os recursos financeiros limitados dos clientes e a resistência oferecida pelos proprietários de animais de guarda e companhia no que se refere ao esclarecimento da causa da doença de seus animais através de exames laboratoriais complementares dificultam os estudos a respeito da prevalência dessa condição nas populações felinas locais nas diversas regiões do Brasil.

O presente estudo tem como objetivo descrever os aspectos clínicos e patológicos de casos adicionais de cirrose biliar em três felinos associados à ectasia do ducto cístico e formação de desvios portossistêmicos extra-hepáticos.

\section{MATERIAL E MÉTODOS}

O histórico e os sinais clínicos da doença de três felinos atendidos durante os anos de 1999 e 2001 nos Hospitais de Clínicas Veterinárias (HCV) da Universidade Federal de Santa Maria (UFSM) (felino 1) e da Universidade Federal do Rio Grande do Sul (felinos 2 e 3 ) foram obtidos com os veterinários dos estabelecimentos e com os proprietários. Os felinos 1 e 2 foram submetidos à laparotomia exploratória. Foi realizada biópsia cirúrgica em um dos animais (felino 1). Foi realizada ultrassonografia do abdome no felino 2 e radiografia abdominal do 
felino 3. O tratamento dos animais afetados consistiu em terapia de suporte e antibioticoterapia. Os felinos 1 e 2 foram submetidos à laparatomia exploratória. $\mathrm{O}$ felino 1 morreu imediatamente após o procedimento cirúrgico enquanto o felino 2 morreu durante a cirurgia, após parada respiratória. As necropsias dos felinos 1 e 2 foram realizadas imediatamente após a eutanásia. O proprietário não autorizou a realização da necropsia completa no felino 2. Nesse caso, apenas o fígado e a vesícula biliar foram retirados através de necropsia cosmética. Para os felinos 1 e 3, além do fígado, fragmentos de diversos órgãos e o encéfalo foram colhidos, fixados em formol a $10 \%$ e processados rotineiramente para exame histológico. A coloração de Brown-Hoops para identificação de bactérias foi empregada em cortes histológicos de fígado do felino 2. Bile foi colhida de um dos animais (felino 3) para exame bacteriológico. Exames laboratoriais complementares (hemograma completo e dosagens de enzimas hepáticas) não foram realizados uma vez que os proprietários se recusaram a arcar com despesas adicionais ou então pelo fato desses exames não estarem prontamente disponíveis para fins diagnósticos.

\section{RESULTADOS}

Tratava-se de três felinos, duas fêmeas e um macho, com idades que variavam entre quatro e 12 anos, sendo um deles da raça Persa (felino 1), um da raça Angorá (felino 2) e o outro (felino 3 ) sem raça definida. O quadro clínico observado nos animais afetados consistia em icterícia, emagrecimento progressivo, vômitos com eliminação de líquido amarelado, prostração, anorexia, mucosas pálidas ou amareladas e aumento de volume do abdome acompanhado de dor abdominal traduzida por sensibilidade à palpação. O felino 1 apresentava acentuada distensão do abdômen constatada inicialmente há cerca de 15 dias. No caso do felino 3, os sinais clínicos enunciados já vinham sendo observados há cerca de um ano e meio.

A laparotomia exploratória do felino 1 revelou a presença de uma estrutura cística, de aproximadamente $4 \mathrm{~cm}$ de diâmetro, de consistência flutuante, que apresentava comunicação com o duodeno e que foi identificada inicialmente como a vesícula biliar. Optou-se pela retirada dessa estrutura cística junto a todo o lobo hepático quadrado e parte do lobo hepático medial direito. O exame dessa peça cirúrgica revelou que essa estrutura dilatada correspondia, na verdade, ao ducto cístico que estava acentuadamente distendido (ectásico) assumindo formato semelhante ao de uma ampulheta (Figura 1).

O exame ultrassonográfico do abdômen do felino 2 revelou dilatação dos ductos do sistema de drenagem biliar, em especial do ducto colédoco, e estômago repleto e com conteúdo líquido. Durante a celiotomia exploratória desse animal, foi constatado que o fígado apresentava a superfície capsular difusamente irregular, finamente granular, com áreas esbranquiçadas alternadas por áreas alaranjadas, conferindo ao órgão um aspecto reticulado. Adicionalmente, a vesícula biliar e a árvore biliar estavam distendidas, os linfonodos mesentéricos mostravam-se aumentados de volume e havia desvios ("shunts") portossistêmicos venosos extra-hepáticos além da presença de aproximadamente $30 \mathrm{ml}$ de líquido límpido e citrino (ascite). Foi dado o diagnóstico presuntivo de cirrose hepática baseado nas lesões macroscópicas observadas durante a cirurgia.

À necropsia, o fígado desses animais apresentava-se firme e com a superfície natural e de corte irregulares e de aspecto reticulado conferido por linhas esbranquiçadas, espessas, que se entrecruzavam no parênquima hepático e se alternavam com áreas amareladas (Figura 2). Os ductos biliares intra-hepáticos mais calibrosos estavam mais evidentes, ectásicos e esverdeados devido à retenção de bile (colestase). $\mathrm{O}$ felino 1 tinha a vesícula biliar e o ducto cístico preenchidos por conteúdo espesso, viscoso e amarelo esbranquiçado. O felino 3 apresentava, além das lesões hepáticas já mencionadas, "shunts" portossistêmicos extrahepáticos e efusões cavitárias (ascite, hidrotórax e hidropericárdio). Nesse animal, havia aproximadamente $10-30 \mathrm{ml}$ de líquido claro e alaranjado (transudato) preenchendo as cavidades corporais citadas.

Histologicamente, havia fibrose periportal, severa, dissecante, em ponte, com a formação de pseudolóbulos, associada a infiltrados inflamatórios linfoplasmocitários, proliferação e distensão acentuadas dos ductos biliares periportais, dilatação de vasos linfáticos dos espaços-porta, retenção biliar (colestase) hepatocelular, canalicular e ductal e acúmulo de células mononucleares, restos celulares, fibrina e bile na luz dos ductos biliares. Em um dos casos, a coloração especial de Brown-Hopps revelou a presença de cocos gram-positivos na luz dos ductos biliares associados à inflamação. Em um dos felinos (felino 1), havia hiperplasia do epitélio de revestimento da mucosa do ducto cístico com a formação de projeções digitiformes que se orientavam para a luz dessa estrutura tubular. 


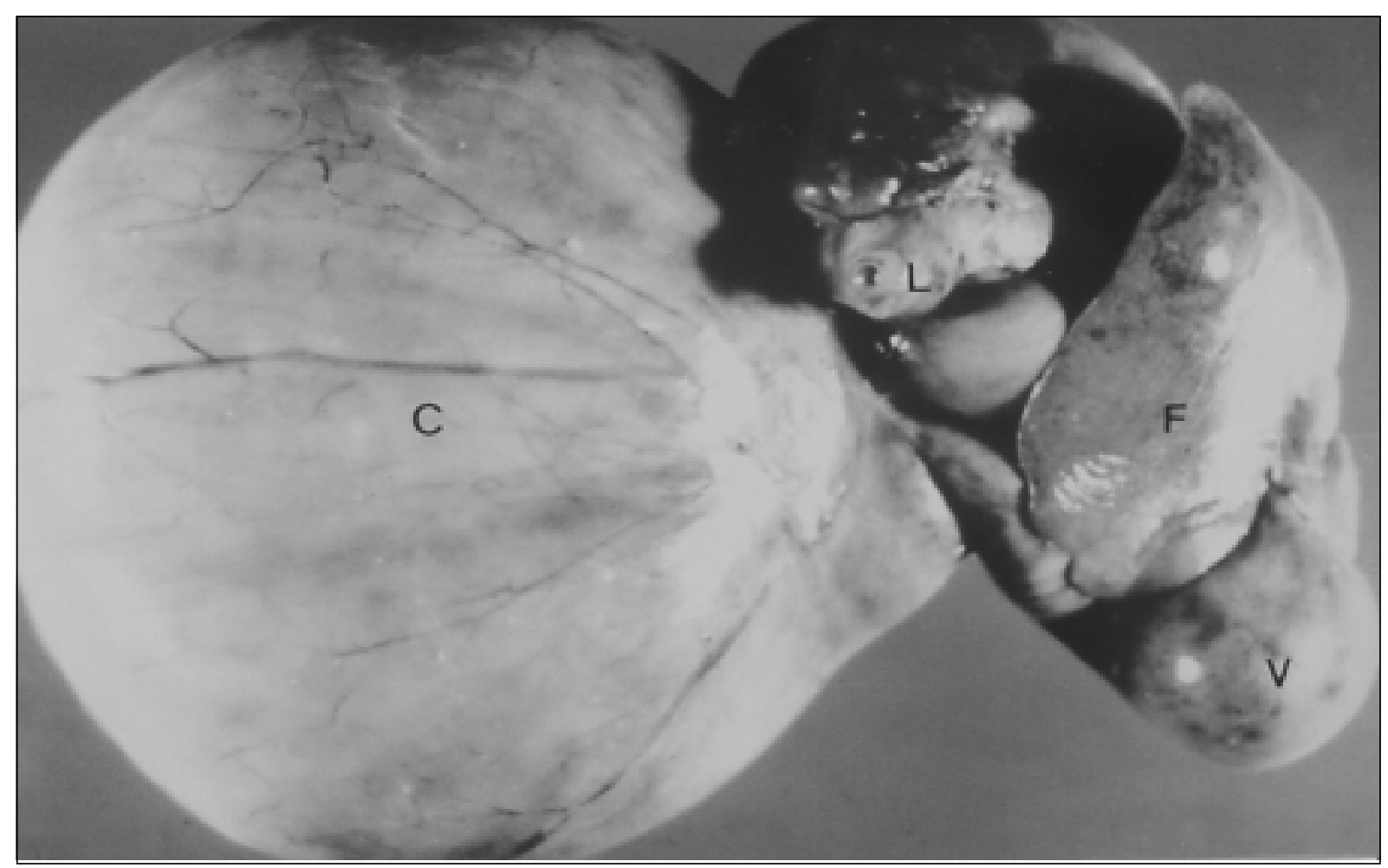

Figura 1 - Felino 1. Fígado (F) e sistema ductal hepático. Ectasia do ducto cístico (C). Ducto cístico acentuadamente distendido, de consistência flutuante. Vesícula biliar (V). Ducto biliar comum, secção transversal (L). Clinicamente esse animal apresentava acentuada distensão abdominal.

O raio-X abdominal do felino 3 não revelou alterações significativas. O exame bacteriológico da bile do felino 3 forneceu resultados negativos.

\section{DISCUSSÃO}

Icterícia, vômitos, dor abdominal e emagrecimento progressivo são sinais clínicos consistentes com doença hepática difusa (insuficiência hepática) em gatos e foram observadas nos três casos de cirrose biliar descritos no presente estudo. O quadro clínico manifestado pelos animais em casos de cirrose biliar não é específico e pode ocorrer em diversas doenças de felinos que provocam icterícia préhepática, hepática ou pós-hepática e caquexia. Essas incluem: (a) o parasitismo por Mycoplasma haemofelis (Haemobartonella felis) (GREENE, 1998), (b) a infecção por Cytauxzoon felis simile (GREENE, 1998, SCOFIELD et al., 2002), (c) a anemia hemolítica auto-imune (FIGHERA et al., 2001), (d) a lipidose hepática idiopática (ZAWIE \& GARVEY, 1984), (e) o diabete melito (ZAWIE \& GARVEY, 1984) (f) o parasitismo por Platynosomum fastosum (GREENE, 1998), (g) a infecção pelo vírus da peritonite infecciosa felina (PIF) (GREENE, 1998), (h) as neoplasias hepatobiliares primárias tais como colangiocarcinoma, carcinoma hepatocelular e linfossarcoma e os tumores metastáticos ou multicêntricos (ZAWIE \& GARVEY, 1984), (i) a cirrose hepática de etiologia multifatorial (ZAWIE \& GARVEY, 1984), (j) a colelitíase (ZAWIE \& GARVEY, 1984) e (k) as doenças associadas à infecção pelo vírus da leucemia felina (FeLV) e vírus da imunodeficiência felina (FIV) p.ex. linfossarcoma multicêntrico (GREENE, 1998). Deve ser ressaltado que a colelitíase tem sido incluída como uma das complicações observadas no $\mathrm{CC} / \mathrm{CH}$ embora alguns autores afirmem que a presença de colélitos na luz da vesícula biliar e dos ductos que formam o sistema de drenagem biliar podem por si só induzir a infecção da árvore biliar provocando colangite ascendente e colangio-hepatite (ZAWIE \& GARVEY, 1984). As marcadas prevalências regionais da hemobartonelose na Região Sudeste do Brasil (Rio de Janeiro e São Paulo) (ALMOSNY et al., 1998) e da infestação por P. fastosum (concinnum) no Estado do Paraná (SHIMADA et al., 2000), São Paulo (CÂNDIDO et al., 2001) e Rio de Janeiro (FERREIRA et al., 1999) 


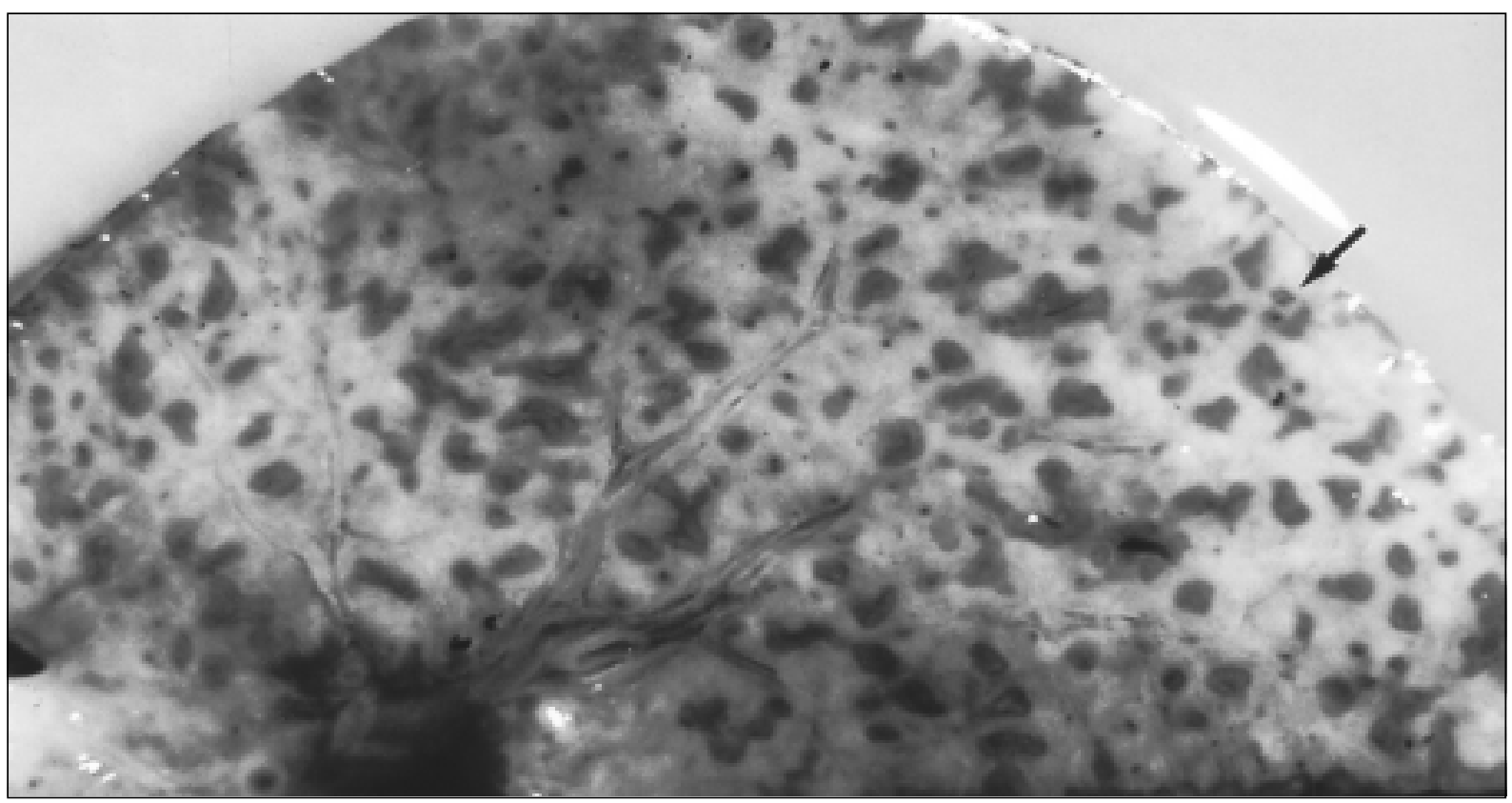

Figura 2 - Felino 2. Fígado com a superfície de corte irregular e de aspecto reticulado conferido por linhas esbranquiçadas, espessas (fibrose) que se entrecruzam no parênquima hepático e que se alternam com áreas mais escuras (parênquima hepático remanescente) (seta).

devem ser levadas em consideração quando essas enfermidades forem incluídas no diagnóstico diferencial da cirrose biliar em populações felinas locais do país. É interessante mencionar que a infecção por M. haemofelis também tem sido descrita esporadicamente na Região Sul do Brasil (FERNANDES et al., 1997; BORTOLINI et al., 2002).

No presente estudo, sugere-se que a cirrose biliar se desenvolveu secundariamente à infecção bacteriana ascendente com invasão dos ductos biliares por microrganismo entéricos. A presença de cocos gram-positivos misturados às células inflamatórias, fibrina e restos celulares acumulados na luz de ductos biliares intra-hepáticos em um dos felinos é uma forte evidência morfológica para sustentar essa hipótese. No entanto, nosso achado é conflitante com os dados da literatura a esse respeito uma vez que tem sido sugerido que, nos casos de $\mathrm{CC} / \mathrm{CH}$, a infecção bacteriana ocorreria durante o estágio inicial e agudo da doença (colangite/colangio-hepatite supurativa), causaria a ativação do sistema imune e este promoveria então um dano hepatocelular progressivo mesmo após a eliminação do microrganismo. Bactérias intralesionais não têm sido descritas em casos de cirrose biliar em felinos. Deve ser ressaltado que a possibilidade de contaminação pós-mortal do parênquima hepático pela flora gastrintestinal normal está descartada, nesse caso, uma vez que o fígado foi retirado da carcaça imediatamente após a morte do animal e, em seguida fixado e processado para exame histológico. Além disso, não foram encontrados bacilos da putrefação, originários da luz do tubo digestivo e que são tipicamente encontrados em vísceras em decomposição/putrefação (autólise). Casos de colangite/colangio-hepatite supurativa associados à infecção ascendente do trato biliar por enterococos têm sido descritos (JACKSON et al., 1994; DAY, 1995). Todavia, a visualização de bactérias no lúmen dos ductos biliares misturados a células inflamatórias em cortes histológicos tem sido descrita em raras ocasiões (LAPOINTE et al., 2000).

Bactérias intestinais tais como $\boldsymbol{E}$. coli, Enterococcus, Bacterioides, Fusobacterium e Streptococcus têm sido isoladas através de culturas aeróbicas e anaeróbicas de amostras de bile e fígado em casos de colangite/colangioepatite supurativa (LEWIS et al., 1991;JACKSON et al., 1994; LAPOINTE et al., 2000). Testes de sensibilidade têm sido feitos nesses casos com o objetivo de selecionar o antibiótico mais eficaz para o tratamento dessa condição (DAY, 1995). No presente relato, resultados negativos foram obtidos a partir do cultivo bacteriológico da bile de uma dos animais que apresentava cirrose biliar. Antibioticoterapia pode ser apontada como uma provável causa do insucesso no isolamento de microrganismos na bile desse paciente. 
O grande número de resultados negativos de exames microbiológicos da bile e do tecido hepático em casos do $\mathrm{CC} / \mathrm{CH}$ também pode ser explicado pela dificuldade do crescimento de bactérias anaeróbicas em laboratório (WEISS et al., 1996). Alternativamente, sugere-se que o agente infeccioso agressor não estava mais presente no sistema hepatobiliar do animal quando foi colhido material para microbiologia dada a cronicidade da lesão hepática e avançado estágio da doença clínica.

A correlação causa-efeito entre obstrução biliar extra-hepática (OBEH) e CC/CH ainda não é totalmente aceita na medicina de felinos. Há autores que afirmam que a inflamação do sistema hepatobiliar pode ser a causa primária da OBEH ou então um evento que acontece secundariamente à $\mathrm{OBEH}$ (MAYHEW et al., 2002). No presente estudo, sugerese que a acentuada distensão do ducto cístico, observada em um dos casos estava associada a alterações inflamatórias e hiperplásticas no sistema ductal hepático e também à maior viscosidade na bile impedindo seu fluxo normal e eliminação através do sistema de drenagem biliar. Alterações na viscosidade e coloração da bile têm sido descritas como algumas das complicações verificadas no $\mathrm{CC} / \mathrm{CH}$ e têm sido referidas como bile inspissada (ou semelhante a lodo) e "síndrome da bile branca". Tem sido sugerido que a inspissação da bile ocorra devido à infecção bacteriana e colestase crônica. A "síndrome da bile branca" também tem sido associada à colestase intra-hepática acentuada ou obstrução biliar que promoveria o bloqueio do fluxo normal da bile e o impedimento da secreção de pigmentos biliares. Acredita-se que a bile clara, brancacenta, fluida, mucóide e desprovida de pigmentos observada nessa situação seja formada pelas secreções produzidas pelo epitélio da vesícula biliar. Adicionalmente, o trajeto sinuoso do ducto cístico, particularidade anatômica da árvore biliar da espécie felina, também seria um fator predispondente para a ocorrência dessas alterações na consistência da bile. Tais complicações são usualmente diagnosticadas durante a laparotomia exploratória ou necropsia como no caso aqui descrito. O prognóstico é desfavorável nessas situações complicadas (DAY, 1995).

No presente estudo, sugere-se que o acúmulo de líquido límpido e translúcido na cavidade abdominal (ascite) e a formação de desvios portossistêmicos venosos extra-hepáticos adquiridos ocorreram em conseqüência de hipertensão portal persistente como seqüela de doença hepática avançada, difusa e crônica (aumento localizado da pressão hidrostática do plasma). Adicionalmente, as efusões cavitárias teriam ocorrido em função do decréscimo da pressão colóido-osmótica do plasma (hipoproteinemia) devido à anorexia e dieta deficiente em proteínas e à insuficiência hepática crônica. Ascite e desvios portossistêmicos extrahepáticos são complicações incomuns nas hepatopatias dos felinos mas têm sido descritas ocasionalmente em casos de cirrose biliar (GORES et al., 1994, DAY, 1995). O acúmulo de quilo na cavidade abdominal (ascite quilosa, quiloperitônio) também é raramente descrito em casos de cirrose biliar em felinos e também é atribuído à hipertensão portal acompanhado da ruptura dos linfáticos intestinais (GORES et al., 1994).

\section{AGRADECIMENTOS}

Os autores agradecem à assistência técnica dos professores do Departamento de Patologia Clinica Veterinária, Faculdade de Medicina Veterinária, Universidade Federal do Rio Grande do Sul (UFRGS), Porto Alegre, RS, Joaquim César Teixeira Fernandes (Setor de Bacteriologia) (exame bacteriológico da bile de um dos felinos) e David Driemeier (Setor de Patologia Veterinária) (realização da coloração especial de Brown-Hopps para bactérias em cortes histológicos de fígado de um dos animais), da médico veterinário do HCV-UFRGS Nina Isabel de Oliveira Baptista (atendimento clínico de um dos felinos e encaminhamento do animal para necropsia).

\section{REFERÊNCIAS BIBLIOGRÁFICAS}

ALMOSNY, N.R.P.; MOREIRA, N.S.; MASSARD, C.L. Erlichiose clínica em gato (Felis catus). Rev Bras Ciência Vet, v.5, n.2, p.82-84, 1998.

BORTOLINI, E.C.; BARCELLOS, H.A.; GONZALES, J.C. Incidência de Haemobartonella canis e H. felis como causa de anemia em cães e gatos no hospital veterinário da Universidade de Passo Fundo entre maio e junho de 2002. In: CONGRESSO BRASILEIRO DE MEDICINA VETERINÁRIA (CONBRAVET), 29., 2002, Gramado, RS. Anais... Porto Alegre : SOVERGS, 2002. SPS, 1194 (CDrom).

CÂNDIDO, T.C. et al. Lesões hepáticas em gatos parasitados por Platynosomum fastosum. In: ENCONTRO NACIONAL DE PATOLOGIA VETERINÁRIA (ENAPAVE), 10., 2001, Pirassununga, SP. Resumos... Jaboticabal : Funep, 2001. p.77.

CULLEN, S.; CHAPMAN R. Aetiopathogenesis of primary sclerosing cholangitis. Best Pract Res Clin Gastroenterol, v.15, n.4, p.577-589, 2001.

DAY, D.G. Feline cholangiohepatitis complex. Vet Clin North Am: Small Anim Pract, v.25, n.2, p.375-385, 1995.

EDWARDS, D.F.; McCRAKEN, M.D.; RICHARDSON, D.C. Sclerosing cholangitis in a cat. J Am Vet Med Assoc, v.182, n.7, p.710-712, 1983.

FERNANDES, R.R. et al. Relato inédito de dois casos de hemobartonelose felina no município de Santa Maria - RS nos 
anos de 1996/1997. In: JORNADA INTEGRADA DE PESQUISA, EXTENSÃO E ENSINO DA UFSM, 4., 1997, Santa Maria, RS. Anais... Santa Maria : UFSM, 1997. p.667.

FERREIRA. A.M.R.; ALMEIDA, E.C.P.; LABARTHE, N.V. Liver fluke infection (Platynosomum concinnum) in brazilian cats; prevalence and pathology. Feline Practice, v.27, n.2, p.19-22, 1999.

FIGHERA, R.A. et al. Anemia hemolítica auto-imune em gatos. In: ENCONTRO NACIONAL DE PATOLOGIA VETERINÁRIA (ENAPAVE), 10., 2001, Pirassununga, SP. Resumos... Jaboticabal : Funep, 2001. p.50

GAGNE, J.M., et al. Clinical features of inflammatory liver disease in cats: 41 cases (1983-1993). J Am Vet Med Assoc, v. 214, n. 4, p. $513-516,1999$

GAGNE, J.M.; WEISS, D.J.; ARMSTRONG, P.J. Histopathologic evaluation of feline liver disease. Vet Pathol, v.33, p.521-526, 1996.

GORES, B.R. et al. Chylous ascites in cats: nine cases (19781993). J Am Vet Med Assoc, v.205, n.8, p.1161-1164, 1994.

GREENE, C.E. Infectious diseases of dog and cat. 2.ed. Philadelphia : Saunders, 1998. 934p.

JACKSON, M.W.; PANCIERA, D.L.; HARTMANN, F. Administration of vancomycin for treatment of ascending bacterial cholangiohepatitis in a cat. J Am Vet Med Assoc, v.214, n.4 p.513-516, 1994.

LAPOINTE, J. M. et al. Enterococcus hirae enteropathy with cholangitis and pancreatitis in a kitten. Vet Pathol, v.37, p.282$284,2000$.

LEWIS, D.T. et al. Cholangiohepatitis and choledochectasia associated with Amphimerus pseudofelineus in a cat. J Am Animal Hosp Assoc, v.27, n.2, p.156-162, 1991.

MAYHEW, P.D. et al. Pathogenesis and outcome of extrahepatic biliary obstruction in cats. J Small Anim Pract, v.43, p.247253,2002
MOURA, L.R.C. et al. Colangite/colangio-hepatite supurativa felina. In: CONGRESSO BRASILEIRO DE CLÍNICOS VETERINÁRIOS DE PEQUENOS ANIMAIS, 18., 1996, Recife, PE. Anais... Recife : ANCLIVEPA, 1996. p.162.

NAKAYAMA, et al. Three cases of feline sclerosing lymphocytic cholangitis. J Vet Med Sci, v.54, n.4, p.769$771,1992$.

PANTIN, M.A.; HAGIWARA, M.K.; CARVALHO, C.F. Diagnóstico e tratamento de colangio-hepatite em um gato. In: CONGRESSO BRASILEIRO DA ANCLIVEPA, 15., 1993, Rio de Janeiro, RJ. Anais... Rio de Janeiro : ANCLIVEPA- RJ, 1993. p.50.

SCOFIELD, A. et al. Tipos morfológicos intra-eritrocitários de Cytauxzoon felis simile em gatos domésticos do Brasil. In: CONGRESSO BRASILEIRO DE MEDICINA VETERINÁRIA (CONBRAVET), 29., 2002, Gramado, RS. Anais... Porto Alegre : SOVERGS, 2002. p.1356.

SHIMADA, M.T. et al. Platynosomum fastosum (sin. concinnum) em gato - relato de caso. In: REUNIÓN ARGENTINA DE PATOLOGIA VETERINARIA(RAPAVE), 2, 2000, Corrientes, Argentina. Acta de resumenes... Corrientes : Universidad Nacional del Nordeste, 2000. p.114-115.

VIERLING, M. Animal models for primary sclerosing cholangitis. Best Pract Res Clin Gastroenterol, v.15, n.4, p.591-610, 2001.

WEISS, D.J.; GAGNE, J.M.; ARMSTRONG, P.J. Inflammatory liver disease in cats. Compend Contin Educ Pract Vet, v.23, n.4, p.364-373, 2001.

WEISS, D.J.; GAGNE, J.M.; ARMSTRONG, P.J. Relationship between inflammatory hepatic disease and inflammatory bowel disease, pancreatitis, and nephritis in cats. J Am Vet Med Assoc, v.209, n.6, p.1114-1116, 1996

ZAWIE, D.A.; GARVEY, M.S. Feline hepatic disease. Vet Clin North Am: Small Anim Pract, v.2, p.1201-1230, 1984. 